\title{
EVALUATION OF USED CONVENTIONAL ANALYTICAL METHODS FOR THE DESIGN OF FOLDED PLATES THROUGH A COMPREHENSIVE 3-DIMINSIONAL ANALYSIS
}

\author{
Ahmed Abdel-Raheem Fargaly \\ Civil Engineer in Assuit University, Assiut, Egypt \\ Aly G. Aly , Fayez k. and Hosny M. S. \\ Civil Engineering Department, Faculty of Engineering, Assuit Universty, \\ Assiut, Egypt
}

(Received August 6, 2006 Accepted September 9, 2006)

\begin{abstract}
Conventional method used in analysis of folded plates structures is based on assumptions stating that the connections between plates in transverse direction are assumed rigidly supported, but actually these connections suffer space displacements and deformations, which emphasizes the no reality of such assumption. Consequently, the actual induced internal forces will be different from those calculated by the conventional method. A comprehensive 3-dimensional analysis using F.E. technique has been carried out for the structure as a whole to clarify the difference of the obtained straining actions compared with the conventional method. The comparison showed that for a certain folded plate configuration and number of vents, there is a great difference in the staring actions in both magnitude and direction depending on the location of the transverse cross section in the longitudinal direction. Furthermore, the forces and stresses in plates in the longitudinal direction showed a significant decrease compared with these obtained from conventional method due to the inclusion of the interaction effect of the different elements of the whole structure. The study covered two important basic common configurations: trapezoidal with vertical plates and triangular with vertical plates. The following parameters are also taken into account:

-The number of vents (one vent and four vents).

-The angle of inclination between plates.

The comprehensive study in this research clarified the great drawbacks in conventional used method, emphasizing the necessity for using the 3-diminsional analyses for the whole structure (Using commercially available computer analysis programs (SAP2000)) to get realistic results.
\end{abstract}

KEY WORD: folded plate - space analysis - finite element. 


\section{1- INTRODUCTION}

In the last century it was logic to seek simple approaches for solving complicated structures, one of which is folded plate structures. This was due to the lack of modern technologies for dealing with structures having complicated numerical mathematical model.

Recently the appearance of digital computers with very large memories encouraged the use of advanced methods like finite element technique and the availability of computer programs as a soft ware to deal with such complicated highly indeterminate structures.

Finite element method has been used to analyzing folded plate structure. The structure has been divided into small shell elements. SAP2000 program is used in the analysis. The model provides the actual behavior of the structure as a one-unit space structure; this mathematical model is more realistic for explaining the actual behavior of the structure.

In this study, light focused on two common configureurations of folded plates named triangular and trapezoidal shapes. Folded or hipped-plates structures consisted of an assembly of flat plate strips intersecting at fold lines and arranged such that they form a stable three-dimensional structure. Prismatic structures must be stiffened by diaphragms in at least two cross section.

In traditional method the following assumption are usually made in the computation:

i. The structure is monolithic and the joints are rigid.

ii. The material is elastic, homogeneous and isotropic.

iii. The length of each plate is more than twice its width.

iv. In all plates, plane sections remain plane after deformation.

\section{2- NUMERICAL STUDY}

\section{i- Trapezoidal folded plat}

The regular, one-bay, trapezoidal-folded plate was analyzed. The geometry is shown in Figure (1).

The second structure analyzed was a regular, four-bay, trapezoidal-folded plate. The geometry is shown below in Figure. 2.

\section{i-1- Description of traditional method procedure}

For analysis these strictures two main actions are considered:

\section{A) Slab action}

In prismatic folded plates, the length of each plate is more than twice its width (assumption iii) that the surface loads are carried by each plate as one way slab supported on the fold lines. This termed as slab action M. Hilal, 1987 [2]. The moments were calculated using three moments equation as shown in figure 3. 


$$
\begin{aligned}
& 2 M_{b} \times 3+M_{c} \times 3=-6 \frac{W_{b c} \times h_{b c}^{3}}{24} \\
& M_{b} \times 3+2 M_{c} \times 6+M_{c} \times 3=-6\left(\frac{W_{b c} \times h_{b c}^{3}}{24}+\frac{W_{c d} \times h_{c d}^{3}}{24}\right)
\end{aligned}
$$

\section{B) Beam action}

The reactions from such slab strips are applied as line loads to the fold lines. The only direction in which each plate can apply a reactive force to resist this line load is parallel to its own surface. The resultant line load therefore resolves into components parallel to the two adjacent plates. The plates in turn carry this edge loading longitudinally between the end diaphragms by beam action are shown in figure 4 .

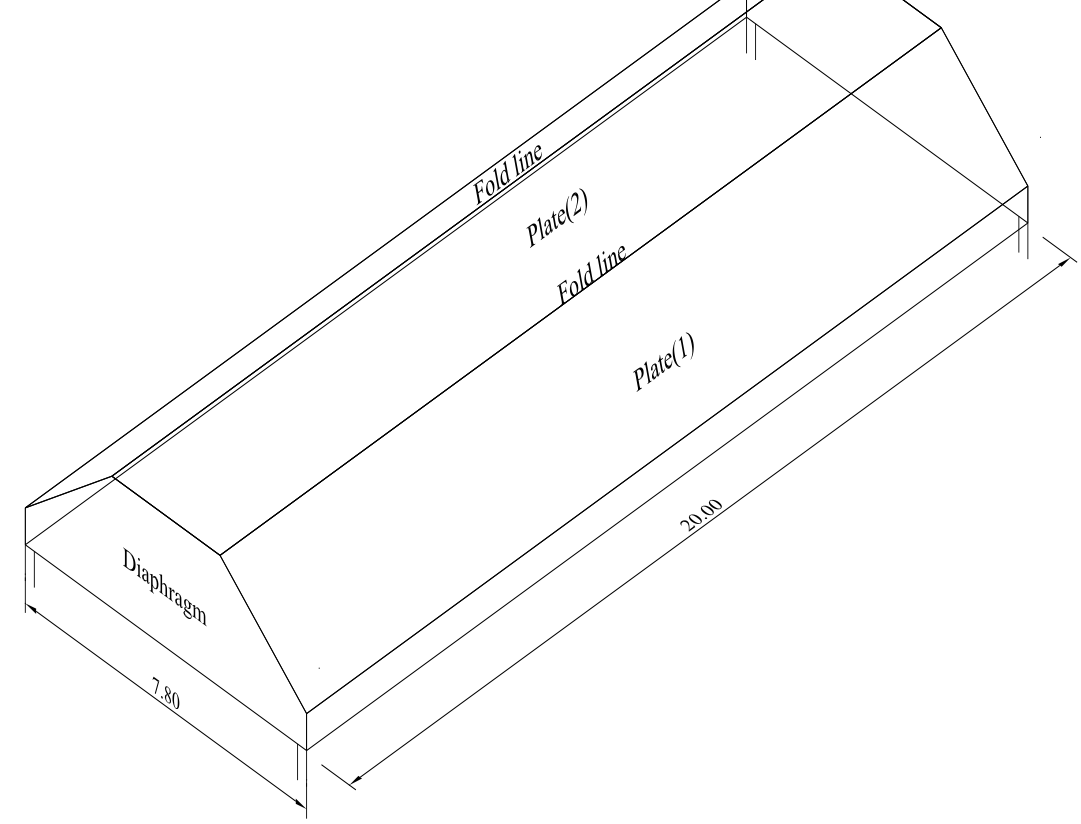

(a) One bay trapezoidal folded plates model

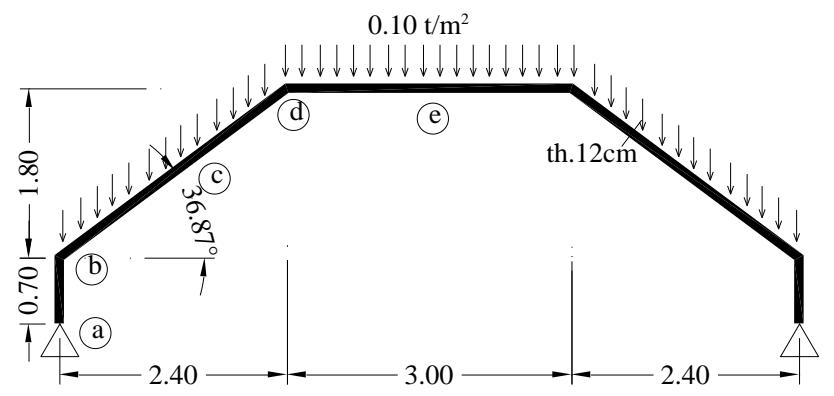

(b) Cross section of trapezoidal folded plates

Figure 1: Geometry, and Loading for one bay Folded Plates. 


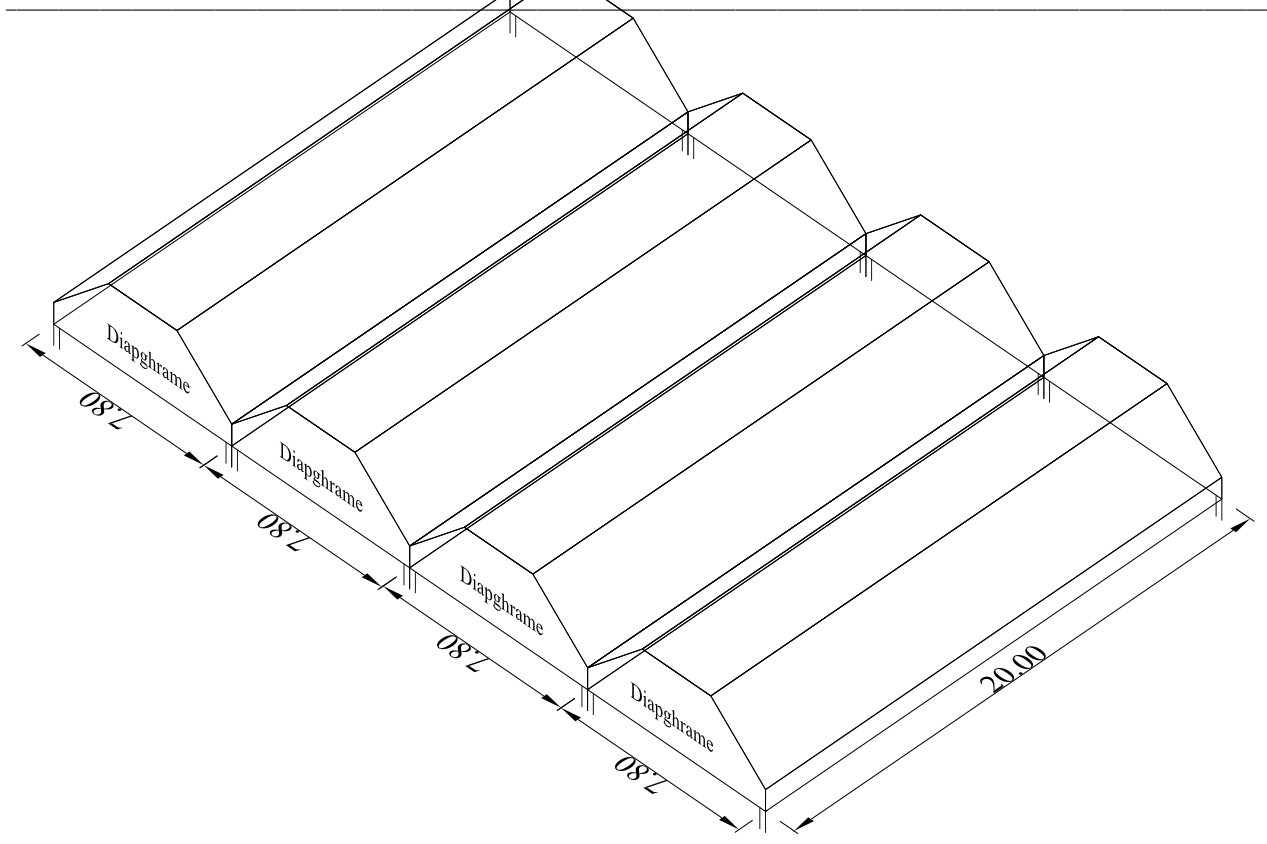

(a) 4- bay 3-d trapezoidal folded plates model

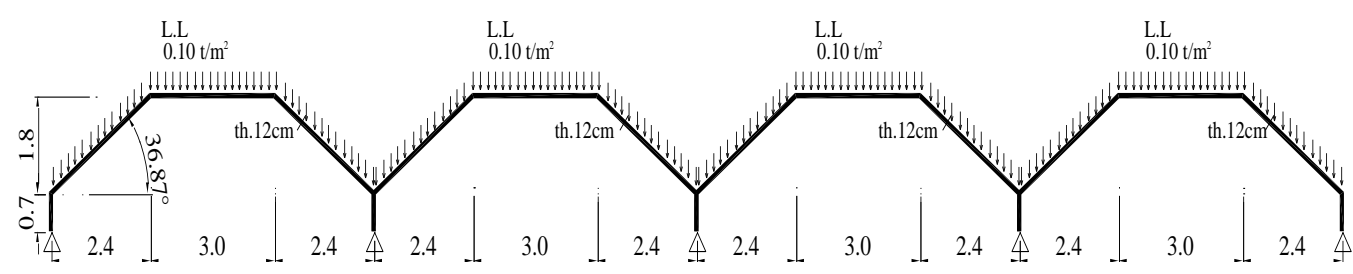

(b)Cross section of trapezoidal folded plates

Figure 2: Geometry, and Loading for one bay Folded Plates

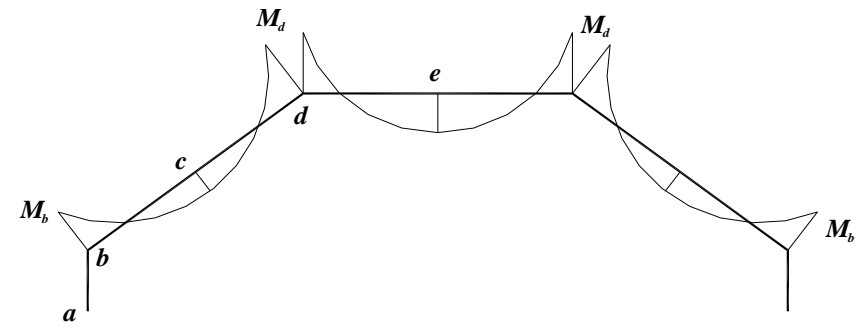

Figure 3: Slab action.

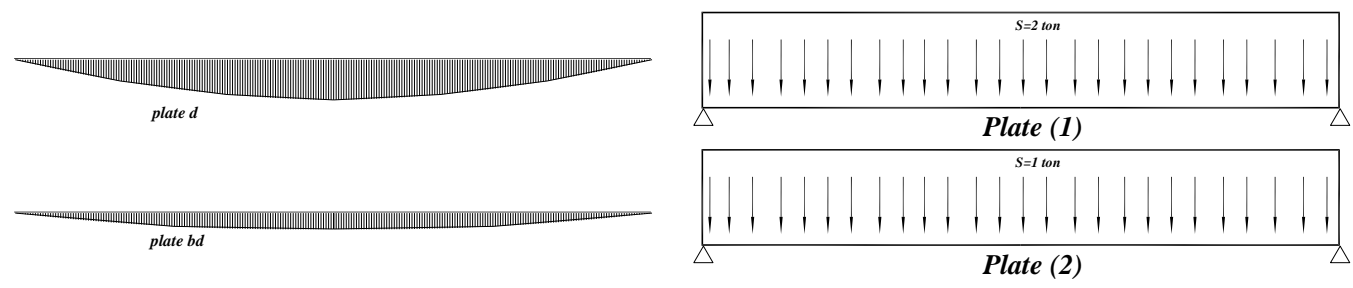

Figure 4: Beam action (longitudinal direction). 


\section{a) Ridge and plate loads}

As shown in figure $\mathbf{5}$ load $\mathrm{Pc}$ applied at ridge $\mathrm{c}$ are known as ridge loads. $\mathrm{Pc}=1 / 2$ (Pc.hc+Pd.hdf) Pc may be resolved into plate loads $\mathrm{Sc}, \mathrm{d}$ and $\mathrm{Sc}, \mathrm{b}$ lying respectively in the planes of the second and third plates by means of a triangle of forces.

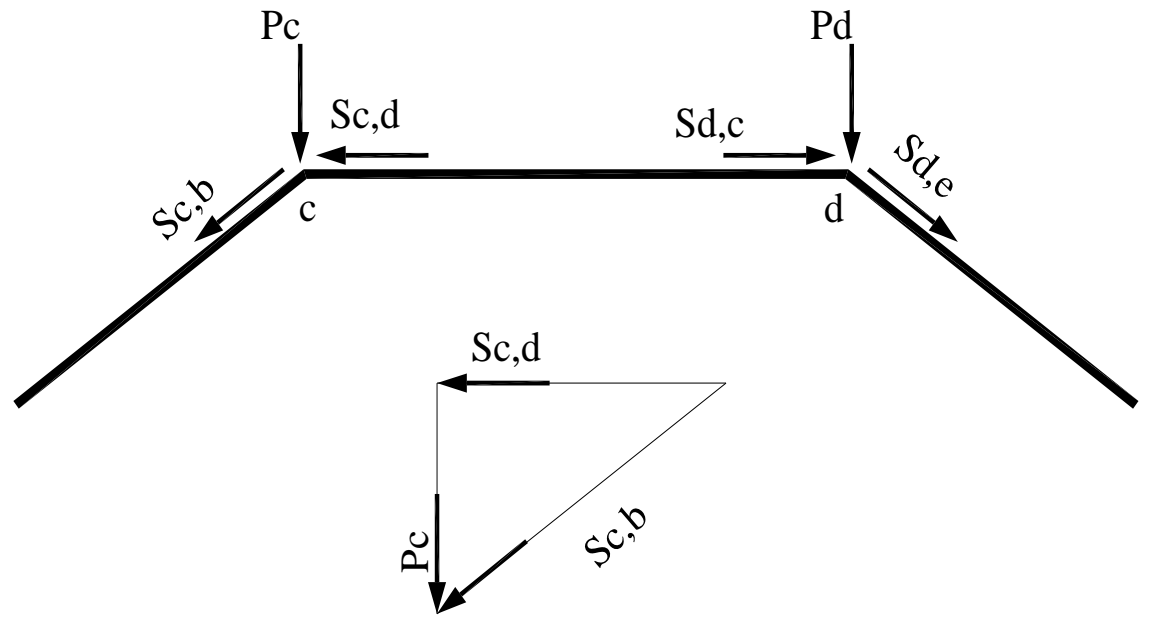

Figure 5: Triangle force .

\section{b) Free stress and compatibility at the ridges}

The distribution of the normal stress in any section of a free plate subject to a bending moments $\mathrm{M}_{0}$ is given by: $\sigma_{b, t}= \pm M_{0} / Z ; \mathrm{Z}=\mathrm{bh}^{2} / 6$.

As shown in figure $6 \mathrm{~T}$ can be calculated as follows: $\sigma_{t, b}=T / A \pm M / Z$ so, $\sigma_{t}=+\frac{4 T}{A}$ and $\sigma_{b}=-\frac{2 T}{A}$

The initial plate analysis indicates a stress difference on either sides of a fold line, an incompatibility is indicated which cannot actually exist because the strains on either sides of a given fold line must be equal. This indicates the presence of longitudinal shear acting along the joint.

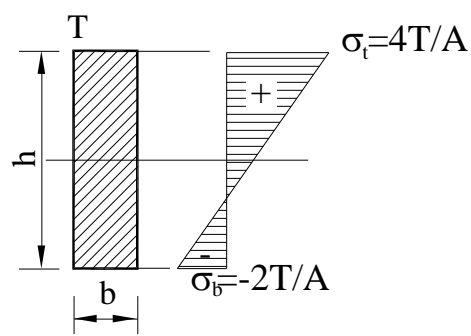

Figure 6: Traditional free edge plate . 
Distribution of edge shear and final stresses:

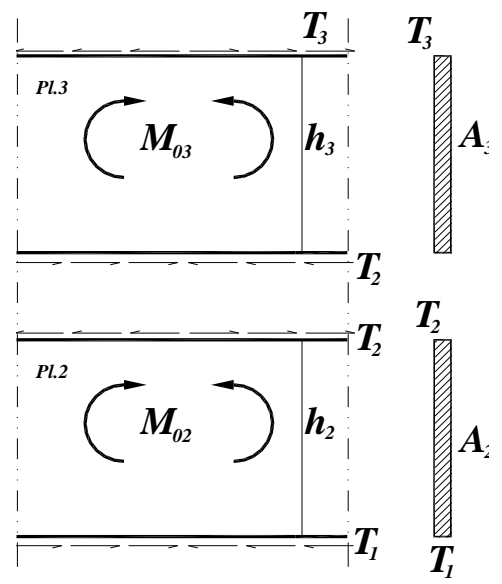

Figure 7: Stresses at joint 2 in plates 2 and 3 .

Figure 7 shows the distributed stresses in plates 1,2. So, bending moments in plates bd and $\mathrm{df}$ is given by the equation:

$M_{0}=\frac{S *(L)^{2}}{8}$.

Applying three-edge shears equation at point $\mathrm{b}, \mathrm{d}$, and $\mathrm{f}$ to get shear value at $\mathrm{d}$ and $\mathrm{f}$

$\frac{T_{1}}{A_{2}}+2\left(\frac{T_{2}}{A_{2}}+\frac{T_{2}}{A_{3}}\right)+\frac{T_{3}}{A_{3}}=\frac{1}{2}\left(\frac{M_{02}}{Z_{2}}+\frac{M_{03}}{z_{3}}\right)$

Where, $T_{1}$ is shear in plate ad, $T_{2}$ is shear at plate bd, $T_{3}$ is shear at plate $\mathrm{df}, \mathrm{A}_{1}$ is cross section area of plate $a b, A_{2}$ is cross section area of plate $b d, A_{3}$ is cross section area of plate $\mathrm{df}, \mathrm{Z}_{1}$ is the section modulus of a plate $\mathrm{ab}, \mathrm{Z}_{2}$ is the section modulus of a plate $\mathrm{bd}$, $\mathrm{Z}_{3}$ is the section modulus of a plate $\mathrm{df}$.

Since each of the $25 \mathrm{~cm}$ wide beams is common for two bays of the folded roof, the beams belonging to one bay are to be introduced with a breadth of $12.5 \mathrm{~cm}$.

As shown in figure 8 (a) the moments were calculated using three moments equation. Moments in longitudinal direction for plate bd and de were calculated in figure 8 (b) by the traditional method. Stresses in mid span section were calculated by traditional method as shown in figure 8 (c).

\section{i-2-Description of computer analysis}

The intent was to investigate the differences between an acceptable "exact" model and various gross approximations used in practice. From the theory of plates and using FEM in the analysis the stresses is distributed in both directions transverse and longitudinal. A shell section is a set of material and geometric properties that describe the cross section of one or more shell elements. Sections are defend independently of the shell elements, and are referenced during the definition of the elements. 


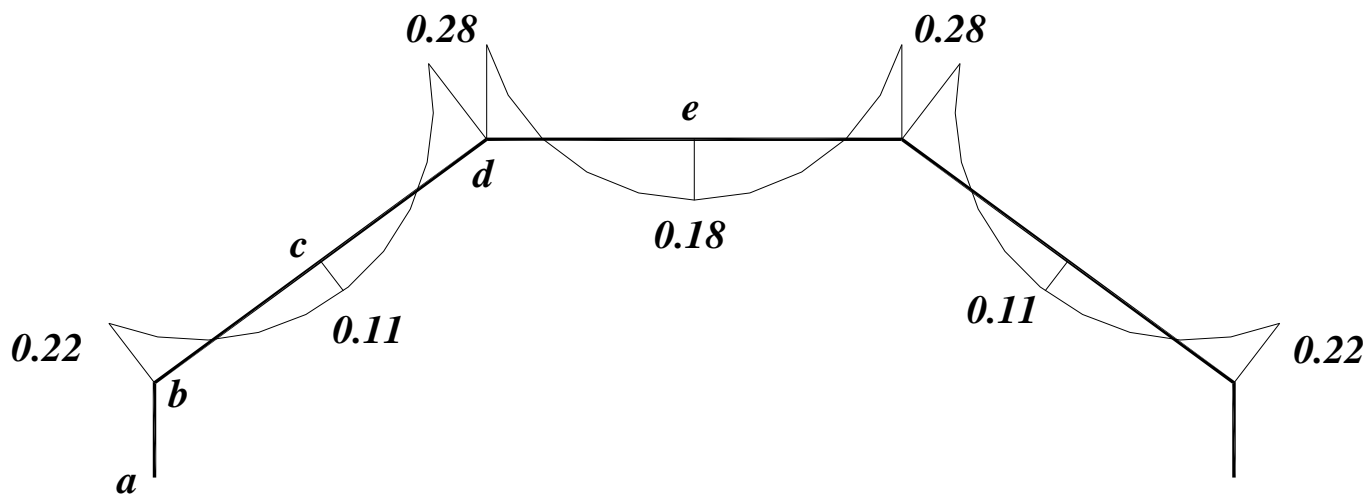

(a) Moment in transverse direction (slab action)(m.t)

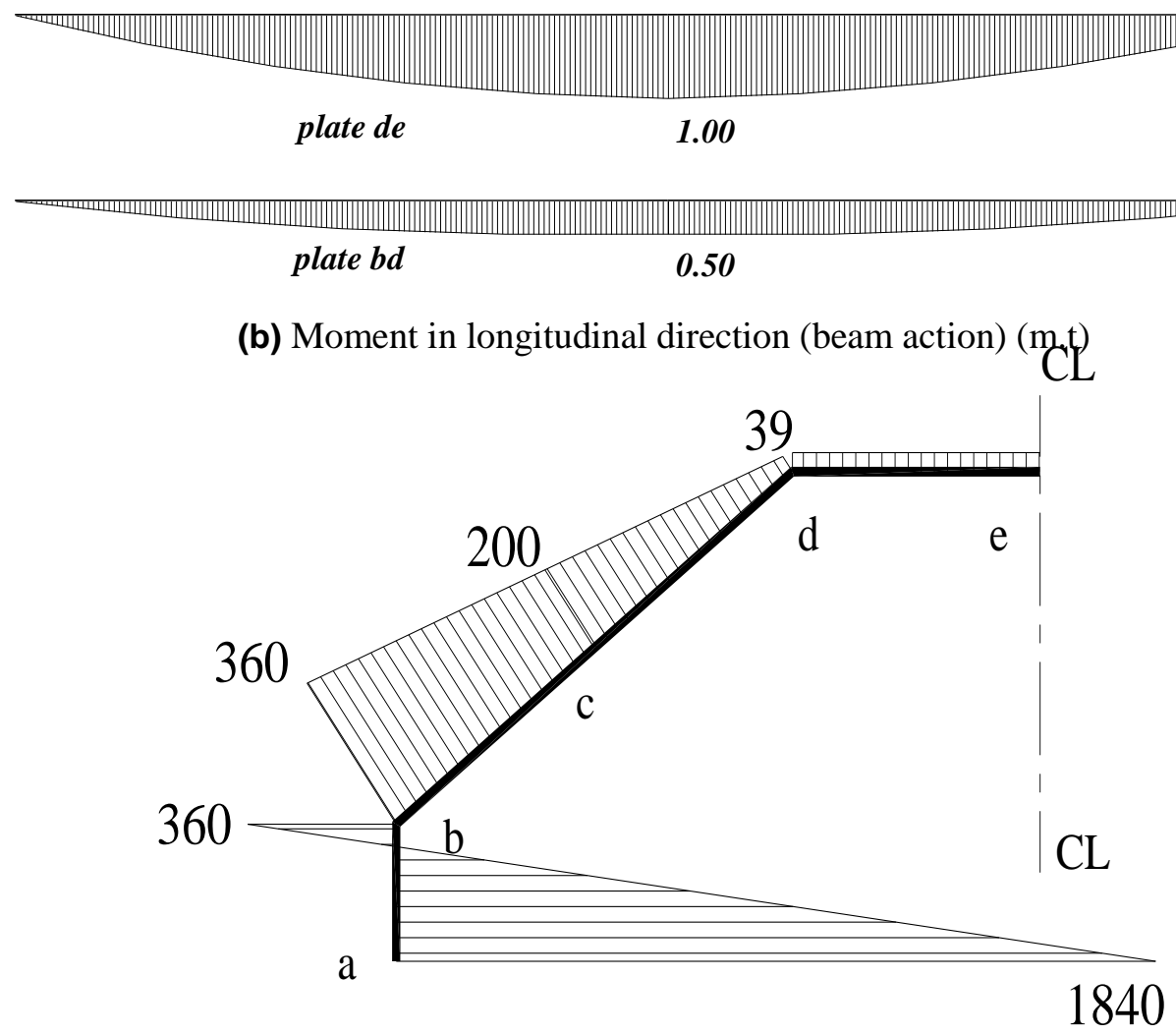

(c) Stresses in transverse direction in mid span ( $\mathrm{t} / \mathrm{m} 2)$

Figure 8: Traditional method actions.

Each shell elements has its own elements local coordinates system used to defined material properties, loads, and output. The axis of local system is denoted 1,2, and 3 the first two axes lay in the plan of the elements with an orientation that you specified, the third axis is normal. Each plate is divided into sum of shell elements. 
As shown in figure 9 the basic shell element stresses are identified as S11, S22, S12, S13, and S23. You might expect that there would also be an S21, but S21 is always equal to $\mathrm{S} 12$, so it is not actually necessary to report $\mathrm{S} 21$. Sij stresses (where i can be equal to 1 or 2 and $j$ can be equal to 1,2 or 3 ) are stresses that occur on face $i$ of an element in direction $\mathrm{j}$. Direction $\mathrm{j}$ refers to the local axis direction of the shell element. Thus S11 stresses occur on face 1 of the element (perpendicular to the local 1 axis) and are acting in the direction parallel to the local 1 axis (that is, the stresses act normal to face 1). As another example, S12 stresses occur on face 1 of the element (perpendicular to the local 1 axis) and are acting in the direction parallel to the local 2 axis (that is, the stresses act parallel to face 1, like shearing stresses) (SAP2000 Analysis Reference, 1997)[3].

As shown in figure 11 (a) the moments in transverse direction (M22 as denoted in the program SAP2000), and in figure 11 (b) moments in longitudinal direction in plate's bd and plate de (M11). Figure 11 (c) presents Total stresses S11 top and S22 top, total S11 bottom and S22 bottom. Each stresses top and bottom gives the value of stresses in the mid height of the thickness. In this analysis the value of sheer stresses (S12 and S23) that found from the analysis results very small with respect to the values give in S11 and S22 stresses, so it will be neglected.

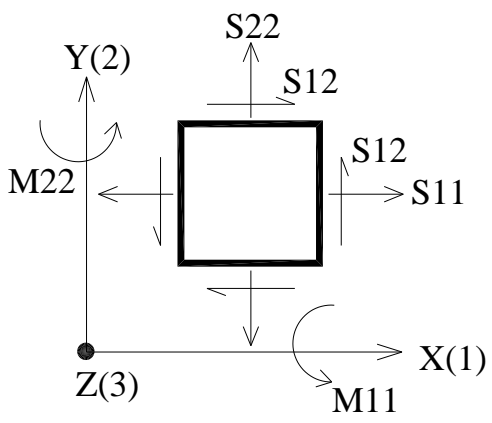

Global coordinates

Figure 9: Shell element forces and stresses.

\section{i-3- Results analysis}

At the same structure geometry the analysis was applied to get the actual differences between two methods of analysis. To calculate the stresses and moments using the traditional method, plates that acted together as supported at fold line. For this structure, five nodes, shown in Figure 8 (b) are compared. At each of the nodes shown in Figure 8, there are differences in the stresses and moments calculated using the traditional method and those predicted by the exact method.

The differences between the transverse moments at node $b$, shown in figure 8(a) and figure 11(a) are greater twice time. At Node d, the moment's variation is small. Again the moments in longitudinal direction compared in values predicted from traditional method and space analysis method in plate bd the value of moment is greater by 10 times from that predicted by space analysis method, in plate de the value is greater by 15 times from that predicted from space analysis method. 
The stresses analysis comparison in the two methods, at node a the values of stresses results from the traditional method is greater than that give from space analysis method by 6 time from space analysis, but the value of node $f$ that in the same geometry location of the section in the space analysis method give that it is smallest by 4 time from traditional method analysis.

At node $b$ stresses from traditional method greater than that predicted from space method by 2 times, and at node $\mathrm{g}$ in space method stresses is smallest by 50 times and inverted in the sing. At node $\mathrm{d}$ the stresses dive from traditional method is smallest by 4 times from space method, node e stresses by space analysis is greater by 6 times from traditional method. General notes in the space analysis are the vary in the values of stresses in the different bay (first bay is different from second bay), and the values of stresses at the first bay is greater that in the second bay, this is because of the effect of lateral free 3-diminsion displacement of this bay.

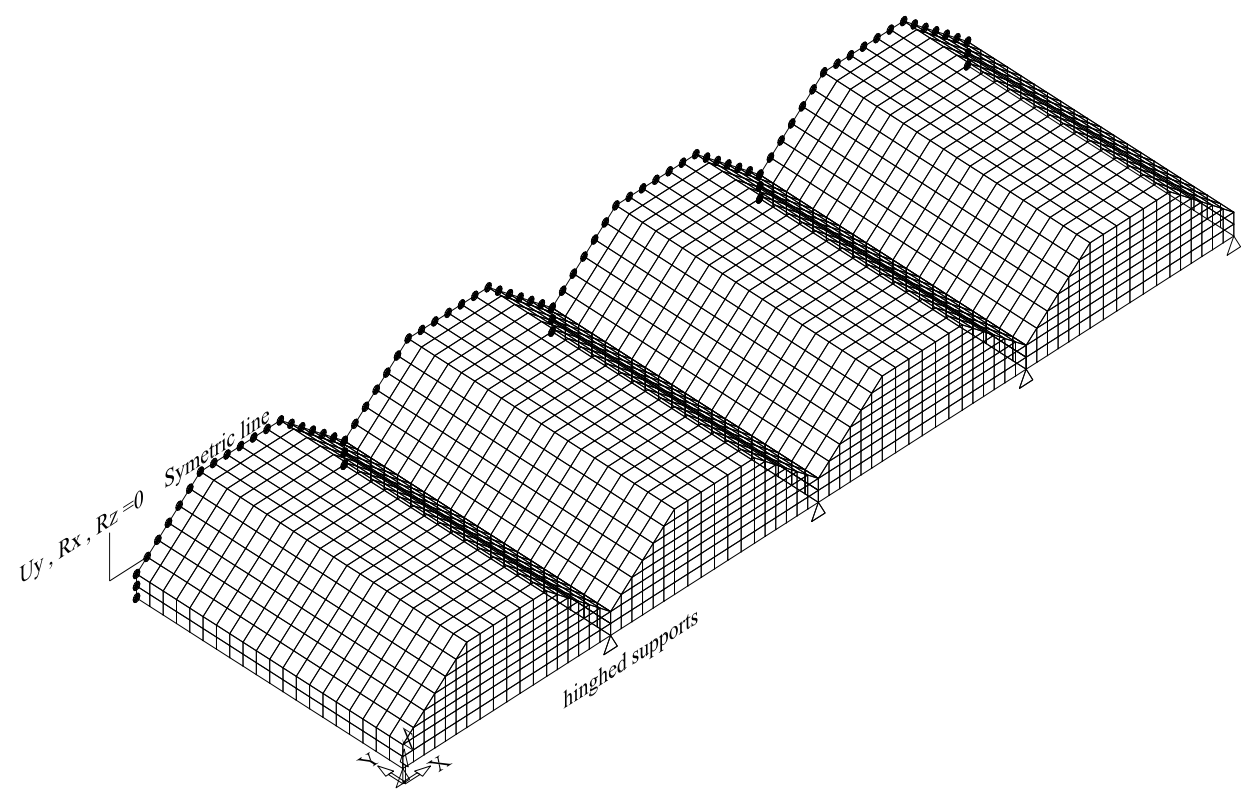

(a) 4- bays 3-d trapezoidal folded plates model.

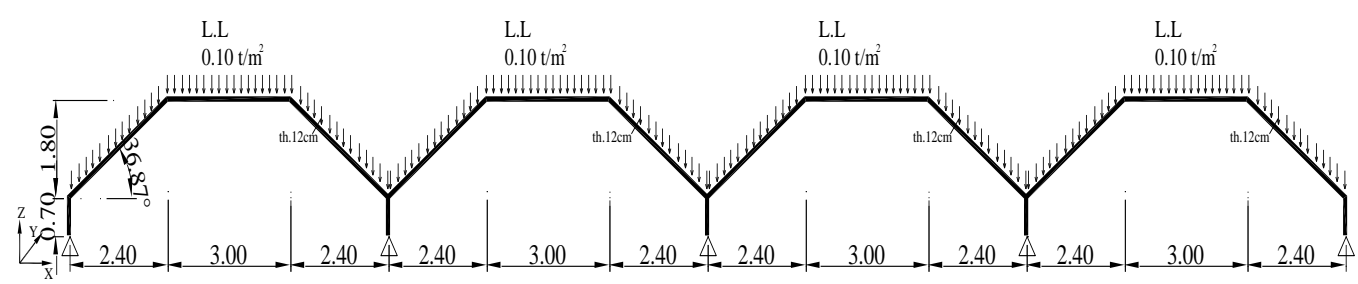

(b) Cross section of trapezoidal folded plates

Figure 10: Geometry, and Loading for 4-bays Folded Plates. 


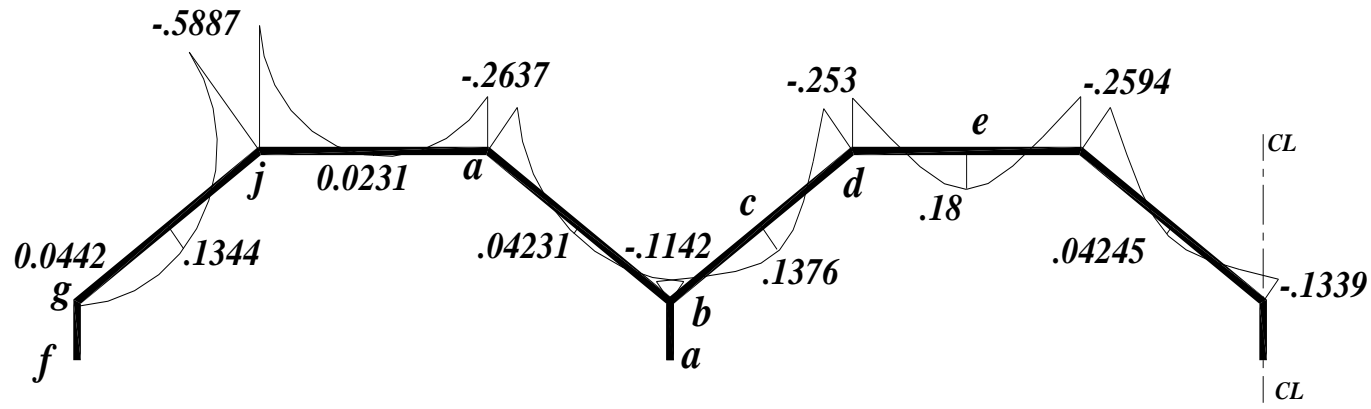

(a) Moment in transverse direction in mid span M22(m.t)

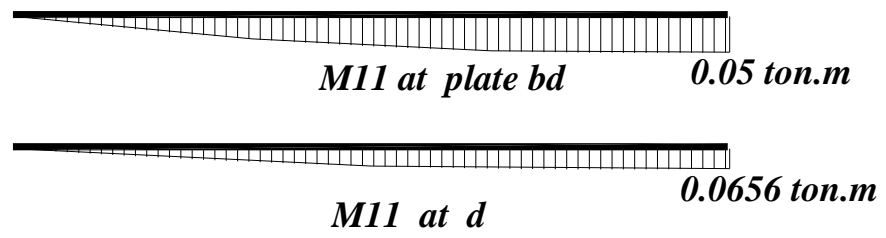

(b) Moment in longitudinal direction in mid span (m.t).

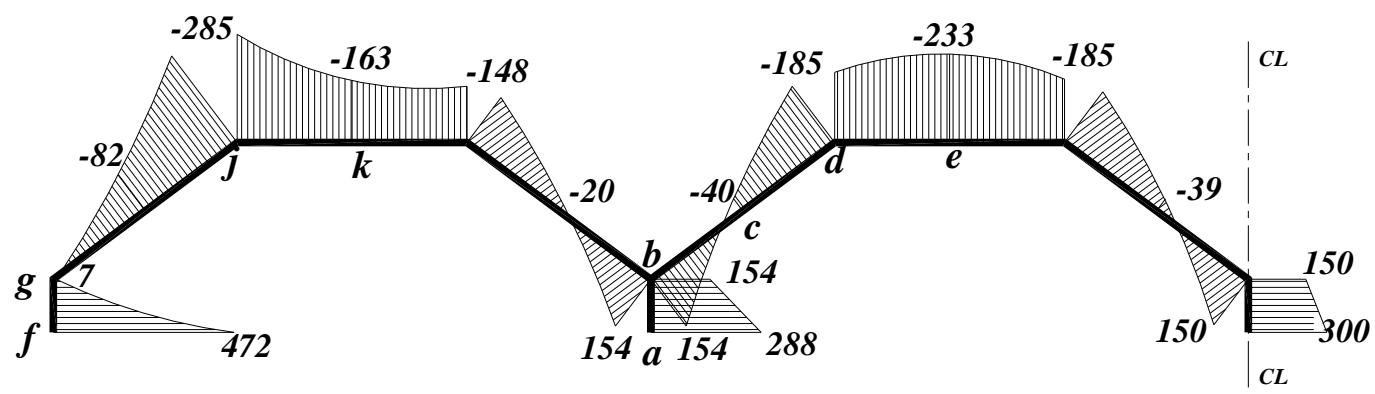

(c) Stresses in mid span $\left(\mathrm{t} / \mathrm{m}^{2}\right)$

Figure 11: Average stresses in mid height of thickness, M22 and M11 using Space analysis method

\section{i-4- Different parameters affecting the analysis of folded plate}

After comparison the results of analysis in both methods traditional and space, this study done to give the convergence and divergence of the values of stresses and moments in the two methods when some factors changed. These factors that will affect the values of results are inclined angles of the plates, number of bays in each structure (4-bays figure 10 above, and one-bay figure 12 below), and the effect of cross section location (At diaphragm, 1m from diaphragm, 5m from diaphragm, and mid span). 


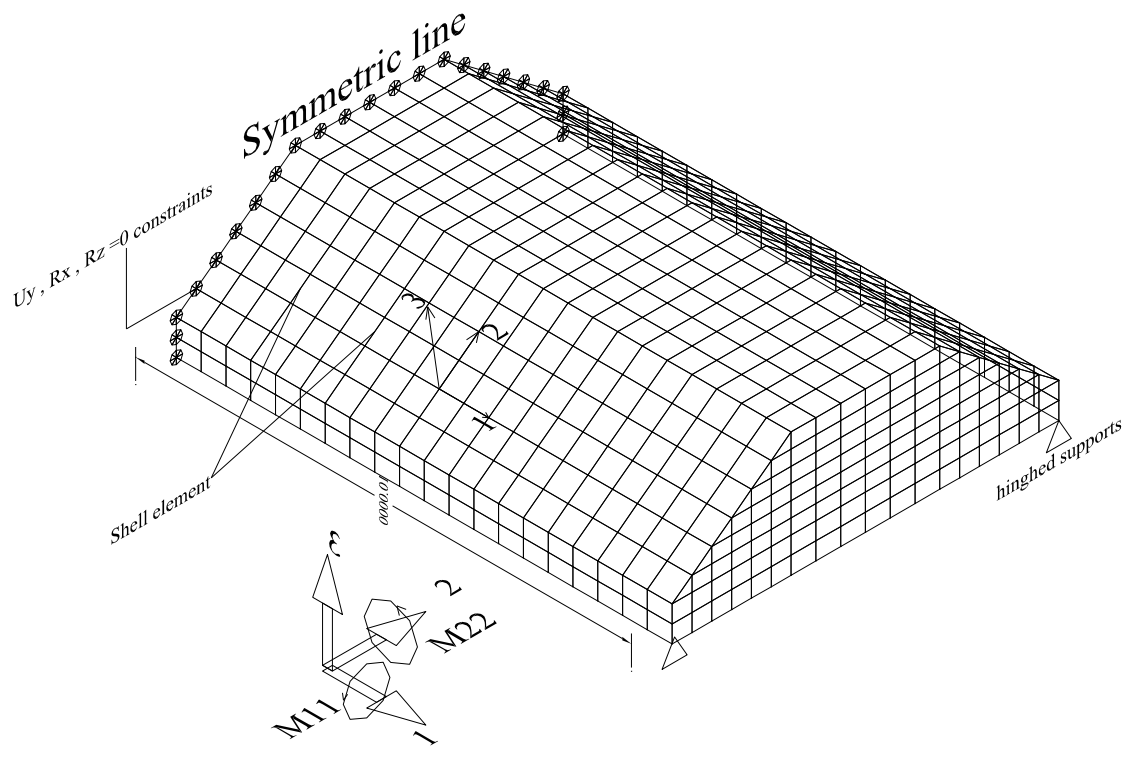

(a) One bay 3-d trapezoidal folded plates model.

$0.10 \mathrm{t} / \mathrm{m}$

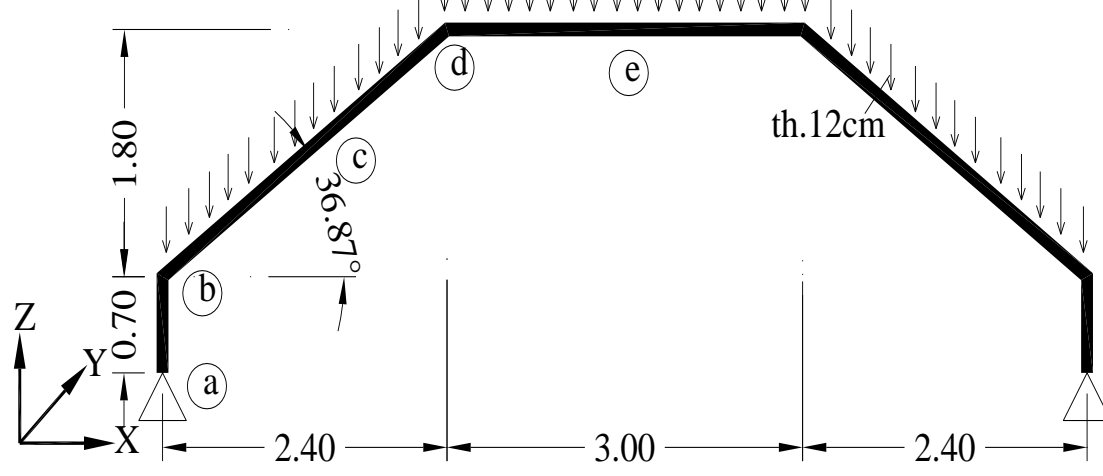

(b) Cross section of trapezoidal folded plates

Figure 12: Geometry, Loading and Sizes for one bay Folded Plates

Figure 13 (a), and (b) shows the effect of various cross-sections and inclined plate angles on Transverse moments of node $b$. It is clear the deference in the values between traditional method and space method specially the values at diaphragm even with these values of space method, the identical values at $1 \mathrm{~m}$, and $5 \mathrm{~m}$ from diaphragm and mid span at all angles. The values of moments at 30 and 36 angles are smallest than all values of moments, but at angles 20, 25, 40, and 45 these values are greater than all values. In the case of one vent all values are positive in space method with negative values for traditional method except in the $1 \mathrm{~m}$ from diaphragm in space analysis that can be coincide with the traditional method. 


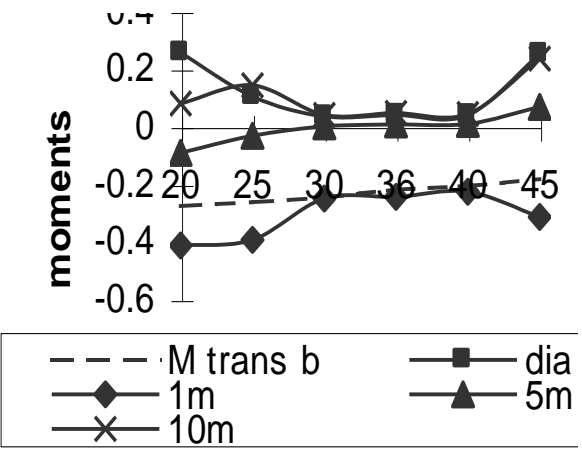

(a) One Vent

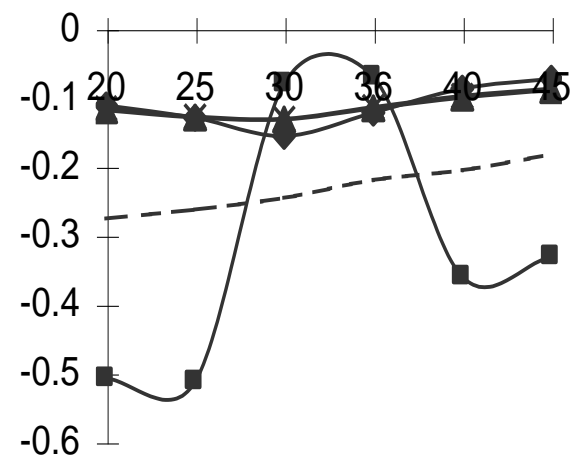

(b) Four Vents

Figure 13: Effect of various cross-sections And inclined plate angles on Transverse moments of node $b$

Figure 14(a), and (b) shows the effect of various cross-sections and inclined plate angles on transverse moments of node $d$. It is clear the close values between traditional method and space method specially the values at $1 \mathrm{~m}$ from diaphragm in angle 25 , and $5 \mathrm{~m}$ from diaphragm, and mid span (10m from diaphragm). The values of moments at diaphragm in all angles are positive.

In the case of one vent all values are negative in space method with negative and average values for traditional method.

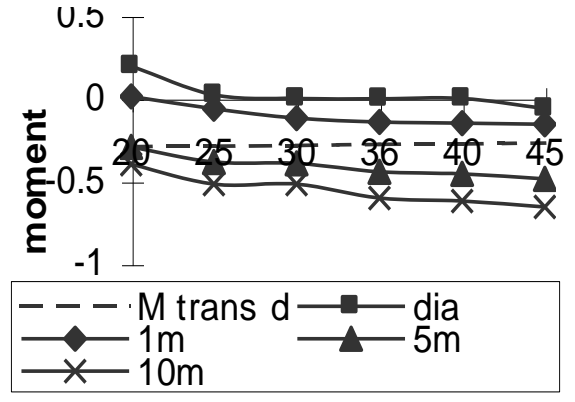

(a) One Vent

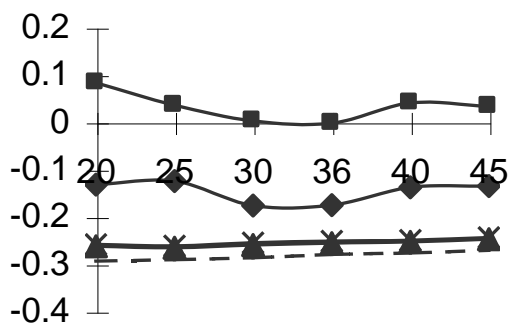

(b) Four Vents

Figure 14: Effect of various cross-sections

And inclined plate angles on Transverse moments of node d (m.t).

Figure 15 (a), and (b) shows the effect of various cross-sections and inclined plate angles on longitudinal moment of plate bd.

It is clear the close values between traditional method and space method specially the values at diaphragm in all angle. The close values of moments in space method specially the values at $1 \mathrm{~m}, 5 \mathrm{~m}$, and $10 \mathrm{~m}$ from diaphragm in all angles. The values of moments at diaphragm in all angles are negative. In the case of one vent the same manner of the moments except in diaphragm that is smaller than that in 4 vents case and also negative sign. 


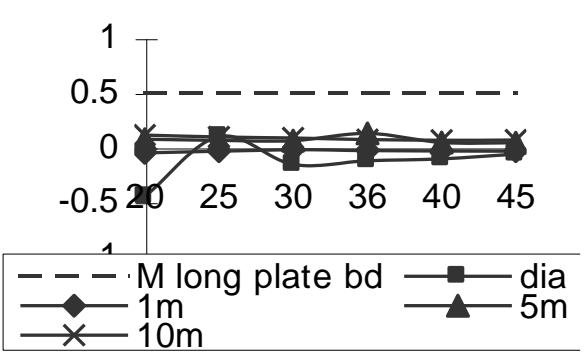

(a) One Vent

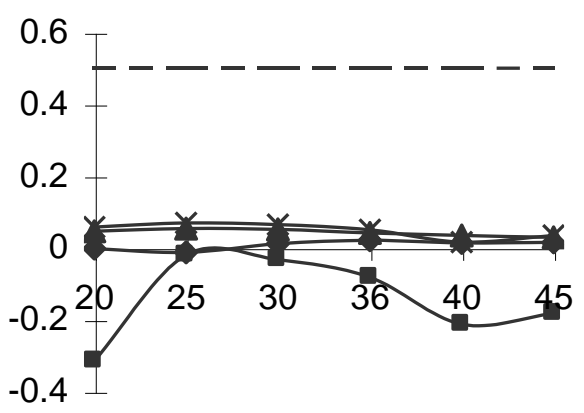

(b) Four Vents

Figure 15: Effect of various cross-sections

And inclined plate angles on longitudinal moments of plate bd (m.t).

Figure 16 (a), and (b) shows the effect of various cross-sections and inclined plate angles on longitudinal moment of plate de. it is clear the close values of moments in space method specially the values at $1 \mathrm{~m}, 5 \mathrm{~m}$, and $10 \mathrm{~m}$ from diaphragm in all angles. The values of moments at diaphragm in all angles are negative.

In the case of one vent the same manner of the moments except in diaphragm that is smaller than that in 4 vents case and also negative sign.

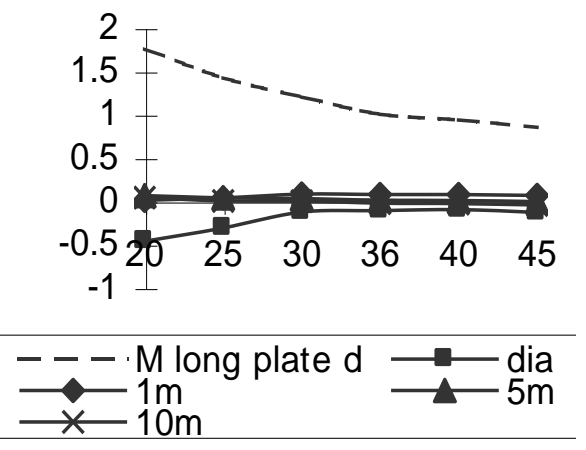

(a) One Vent

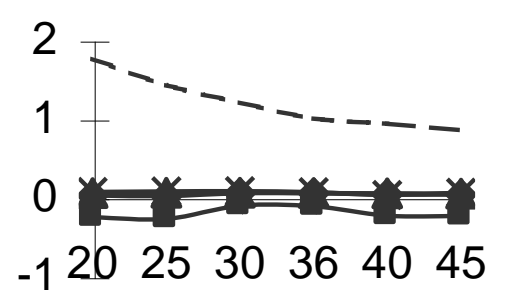

(b) Four Vents

Figure 16: Effect of various cross-sections

And inclined plate angles on longitudinal moments of plate de (m.t).

Figure 17 (a), and (b) shows the effect of various cross-sections and inclined plate angles on stresses of node a. The close values of stresses in space method specially the values at $5 \mathrm{~m}$, and $10 \mathrm{~m}$ from diaphragm in all angles. The values of stresses at diaphragm in all angles are negative and large, that because node (a) is at the support of the diaphragm.

In the case of one the same manner of the stresses except in diaphragm that is smaller than that in 4 vents case and also negative sign. 


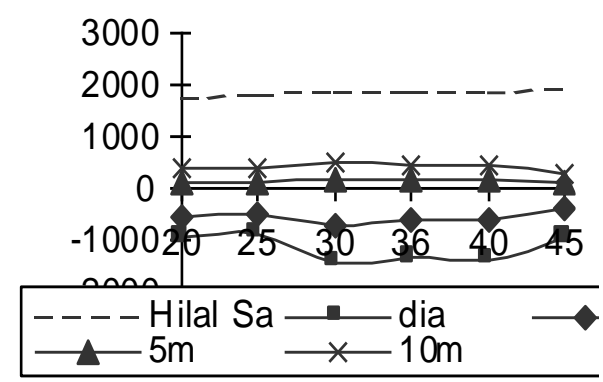

(a) One Vent

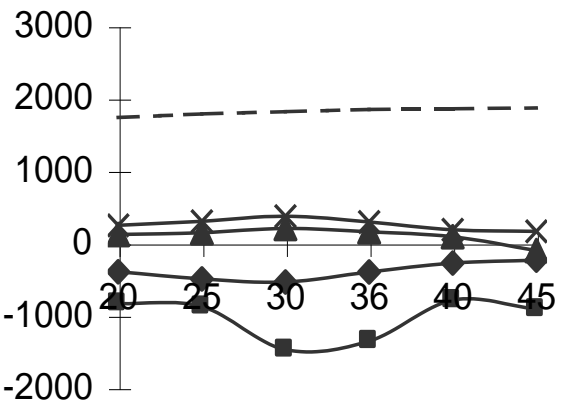

(b) Four Vents

Figure 17: Effect of various cross-sections And inclined plate angles on stresses of node $a\left(t / \mathrm{m}^{2}\right)$.

Figure 18 (a), and (b) shows the effect of various cross-sections and inclined plate angles on stresses of node $b$. It is clear the differences in values between traditional method and space method in all angle. The close values of stresses in space method especially at diaphragm, $5 \mathrm{~m}$, and $10 \mathrm{~m}$ from diaphragm in all angles and these values are all positive except in diaphragm. The values of stresses at $1 \mathrm{~m}$ from diaphragm in all angles are negative and large. The value of stresses in angle between 36 and 40 are coincide in space and traditional methods (the curve of traditional method is intersect with all angles curves).

In the case of one vent the stresses are coincide and small values except in $1 \mathrm{~m}$ from diaphragm that is positive. The values of stresses are smaller than that in 4 vents case and also have positive sign in diaphragm, $5 \mathrm{~m}$, and $10 \mathrm{~m}$. The value of stresses in angle between 36 and 40 are coincide in space and traditional methods (the curve of traditional method intersect all angles curves).

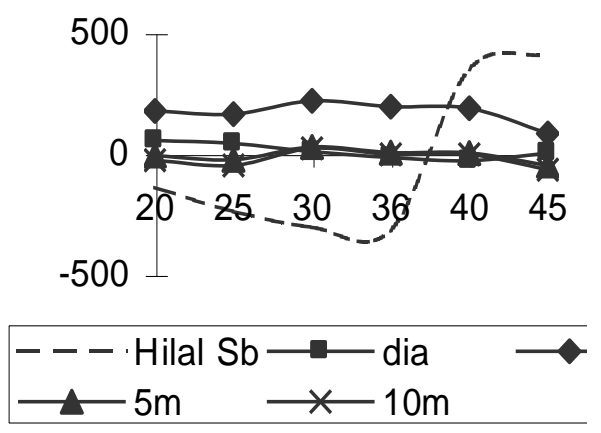

(a) One Vent

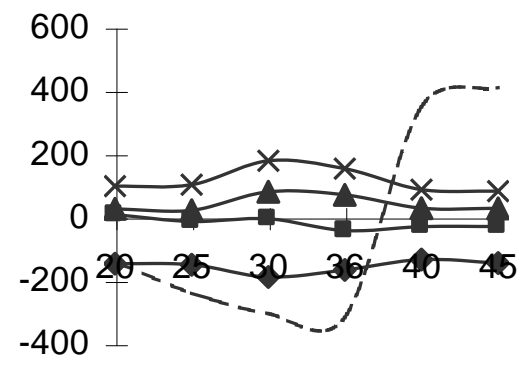

(b) Four Vents

Figure 18: Effect of various cross-sections

And inclined plate angles on stresses of node $b\left(t / \mathrm{m}^{2}\right)$.

Figure 19 (a), and (b) shows the effect of various cross-sections and inclined plate angles on stresses of node $\mathrm{d}$. It is clear the differences values between traditional method and space method in all angle. It can be recognized the close values between 
stresses in space method especially at diaphragm, and $1 \mathrm{~m}$ in all angles. The values of stresses at $5 \mathrm{~m}$ from diaphragm in all angles are negative except in angle 45 and large values. The values of stresses at mid span (10m from diaphragm) are negative and large. The value of stresses in angle between 36 and 40 are coincide in space and traditional methods (the curve of traditional method is intersect with all angles curves diaphragm and $1 \mathrm{~m})$.

In the case of one vent the stresses are small values at diaphragm. In $1 \mathrm{~m}, 5 \mathrm{~m}$, mid span sections the values of stresses are negative. The value of stresses in angle between 36 and 40 are coincide in space and traditional methods in diaphragm and $1 \mathrm{~m}$ (the curve of traditional method is intersect with diaphragm and $1 \mathrm{~m}$ curves).

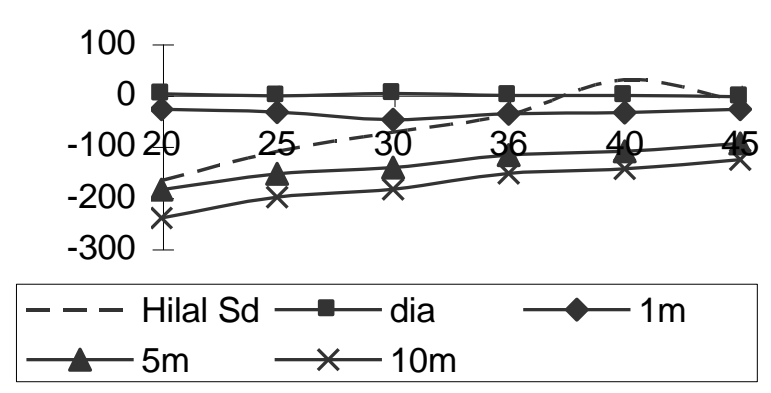

(a) One Vent

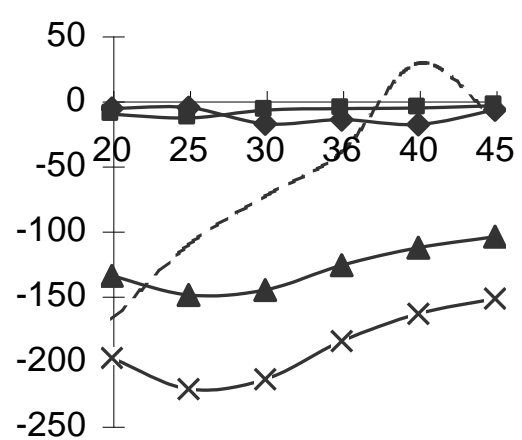

(b) Four Vents

Figure 19: Effect of various cross-sections And inclined plate angles on stresses of node $d\left(t / \mathrm{m}^{2}\right)$.

\section{i-5-Analysis of results}

For 4-vents trapezoidal folded plates in which the plates are inclined with angle 3652 11, the space method predicted transverses moments are almost identical with traditional method in the inner vent mid span section, but in the outer vent the transverses moments are bigger than traditional method by $25 \%$ in node $\mathrm{j}$ that connect outer horizontal plate and outer inclined plate this is because of the large lateral displacements for outer horizontal plate. At nodes $g$, and $b$ the transverses moments are small by $20 \%$ in space method than traditional method in these connection between verticals plates and inclined plate because the large vertical displacements caused by load in these nodes (i.e. the free 3-diminsion displacements of these node in space).

The big difference between the two methods (space and traditional methods) in longitudinal moments as shown in figure $\mathbf{8 ( b )}$, and figure 11(b), that because of the traditional method assume that the total load acts on the nods and then distribute on the inclined, horizontal, and vertical plates, these give a large value of longitudinal moments and the plates are simply supported on the end diaphragms neglecting the effect of moment between diaphragm and plates, but in the space method predicted longitudinal moments are smaller by $100 \%$ in plate bd and $150 \%$ in plate de. 
It is expected that there would be a difference between stresses in both methods since the solution algorithms vary. For node a in traditional method the stress is more than 6 times bigger than that predicted from space method, but for node $\mathrm{f}$ is less than traditional method by 4 times. For node $\mathrm{b}$ the stresses by traditional method are inverse in singe with stresses of space method, this again because of the effect of 3diminsion displacements of this node. For node $f$ in first vent stress is small and have inverse singe with respect to traditional method this because of the large lateral displacements of node $\mathrm{f}$. for node $\mathrm{d}$ in traditional method stress is small by 6 times than that predicted from space method in second vent, but smaller by 7 time for equivalent node $\mathrm{j}$.

Another comparison is made between the moments calculated using the traditional method and predicted by the space. In that respect, for six angles, 4-vents, and 1-vent evaluated in the study, the space method predicts transverses moments very similar to those given by the traditional method analysis in all angles.

For 4-vents and 1-vent, the traditional method gives longitudinal moments very big, with respect to space method. For one-vent longitudinal moments of plat bd for various inclined angles are close values and either close to that predicted from traditional method, but in 4-vents case even these values are close but smaller than that predicted from traditional method, this observation refers to the effect of number of vents. These observations also are identical with longitudinal moments of plate de.

For stresses of node a the same approach of 1-ven and 4-vents cases in space method at all angles and the big differences value between them and traditional method, the biggest negative differences are at diaphragm curves, that because node (a) is the supports of end diaphragms. The values of stresses of node a in space method are positive in all angles at mid span and $5 \mathrm{~m}$ distances, and negative in both curves of $1 \mathrm{~m}$ and diaphragms because it is close to diaphragms, but traditional method consider all stresses at node a at all angles are positive.

The stresses at node $b$ for 1 -vent and 4-vents cases are similar and small in diaphragm, and $5 \mathrm{~m}$ curves with respect to that given by traditional method. In both 1-vent, and 4-vents cases traditional method curve intersect all curves at angle 38.

At node d 4-vents and 1-vent cases have similar approach, but 4-vents case give big stresses for all angles in $5 \mathrm{~m}$ and mid span because of the effect of continuity of vents with respect to smaller values of stresses given from traditional method in these curves.

\section{ii- Triangular folded plate}

The regular, one-bay, Triangular -folded plate was analyzed. The geometry is shown in Figure (20).

As shown in figure $\mathbf{2 1}$ (a) the moments were calculated using three moments equation. Moments in longitudinal direction for plate bd and de were calculated in figure 21(b) by the traditional method. Stresses in mid span section were calculated by traditional method as shown in figure $\mathbf{2 1}$ (c) .

For three-dimension analysis case for triangular folded plates it can be shown in figure 22 the 3-D mesh used for shell division. 
Figure 23 shows the action drive from three-dimension analysis method.

\section{ii-1-Results analysis}

For 4-vents triangular folded plates in which the plates are inclined with angle 3652 11, the space method predicted transverses moments are different from traditional method in the inner vent mid span section, and the outer vent. The transverses moment at node $\mathrm{b}$ is positive and moments at nods $\mathrm{d}$, and $\mathrm{f}$ are almost zero. Moment at node $\mathrm{k}$ is almost equal moment of the same node in traditional method.

At node $b$ stresses from traditional method big than that predicted from space method by 5 times, and at node $d$ in space method stresses is big by 6.5 times. General notes in the space analysis are the vary in the values of stresses in the different bay (first bay is different from second bay), and the values of stresses at the first bay is greater that that in the second bay, this is because of the effect of lateral free 3diminsion displacement of this bay.

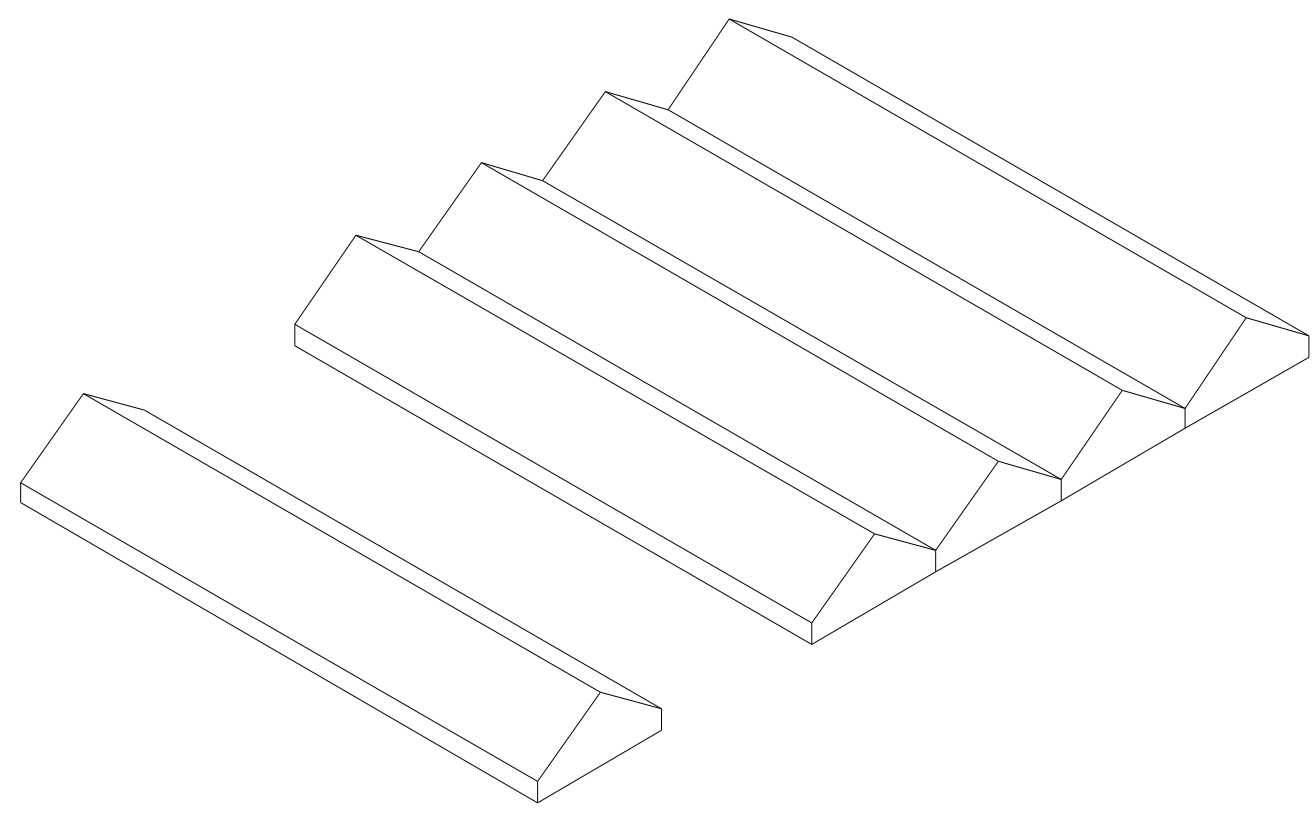

(a) 3-D view of traditional triangular folded plates
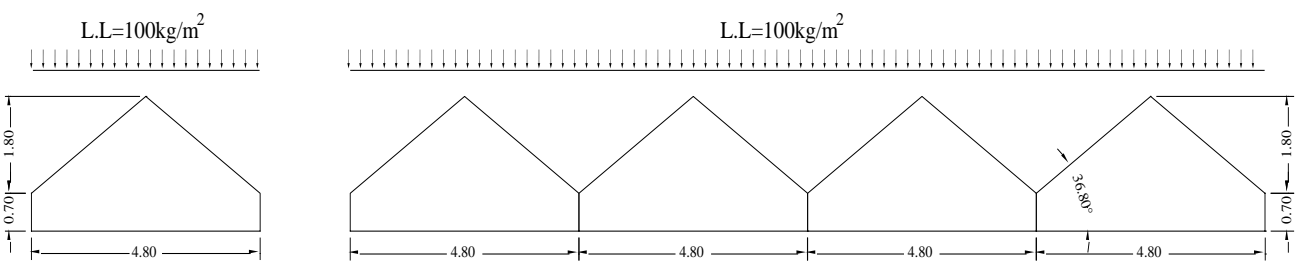

(b) Geometry of triangular folded plates

Figure 20: Geometry, and Loading for one and four bays Folded Plates. 


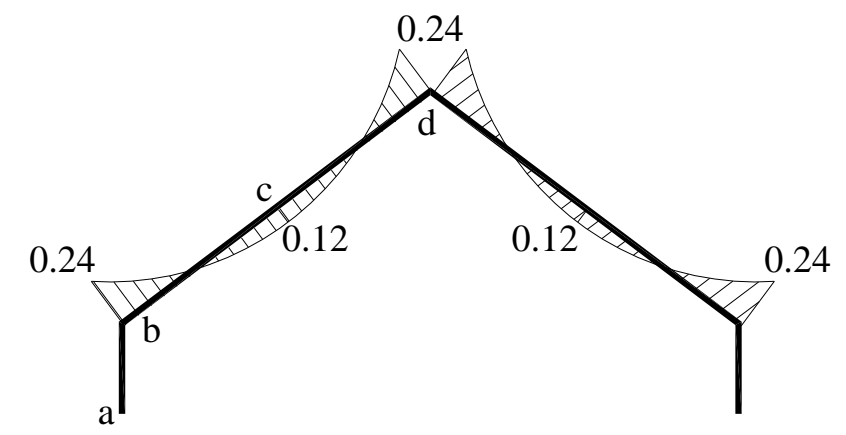

(a) Moment in transverse direction (slab action)(m.t)

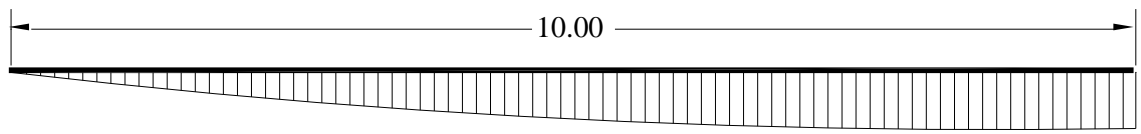

(b) Moment in longitudinal direction for plate bd (beam action) (m.t)

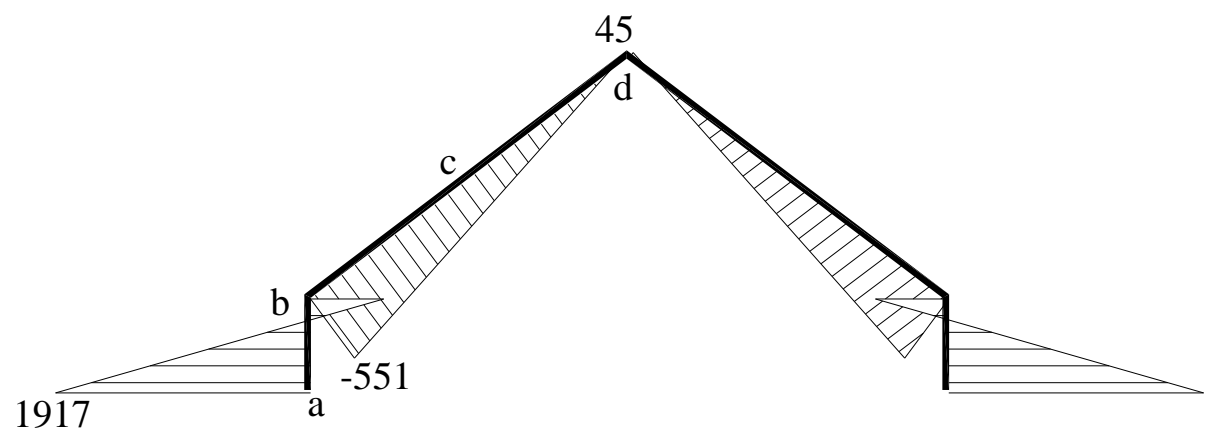

(c) Stresses in transverse direction in mid span $\left(t / \mathrm{m}^{2}\right)$

Figure 21:Traditional method actions.

\section{ii-2- Different parameters affecting the analysis of folded plate}

Some parameters are under go, to give the convergence and divergence of the values of stresses and moments in traditional method and space method. These factors that will affect the values of results are inclined angles of the plates, number of bays in each structure (figure 20), and the effect of cross section location (At diaphragm, 1m from diaphragm, $5 \mathrm{~m}$ from diaphragm, and mid span).

Figure 24 (a), and (b) shows the effect of various cross-sections and inclined plate angles on Transverse moments of node $b$. The deference in the values between traditional methods and space method are shown specially the values at diaphragm even with these values of space method. The values of moments at $10 \mathrm{~m}$ and $5 \mathrm{~m}$ are positive but the values of moments for traditional method are positive as the value of $1 \mathrm{~m}$ moments. 


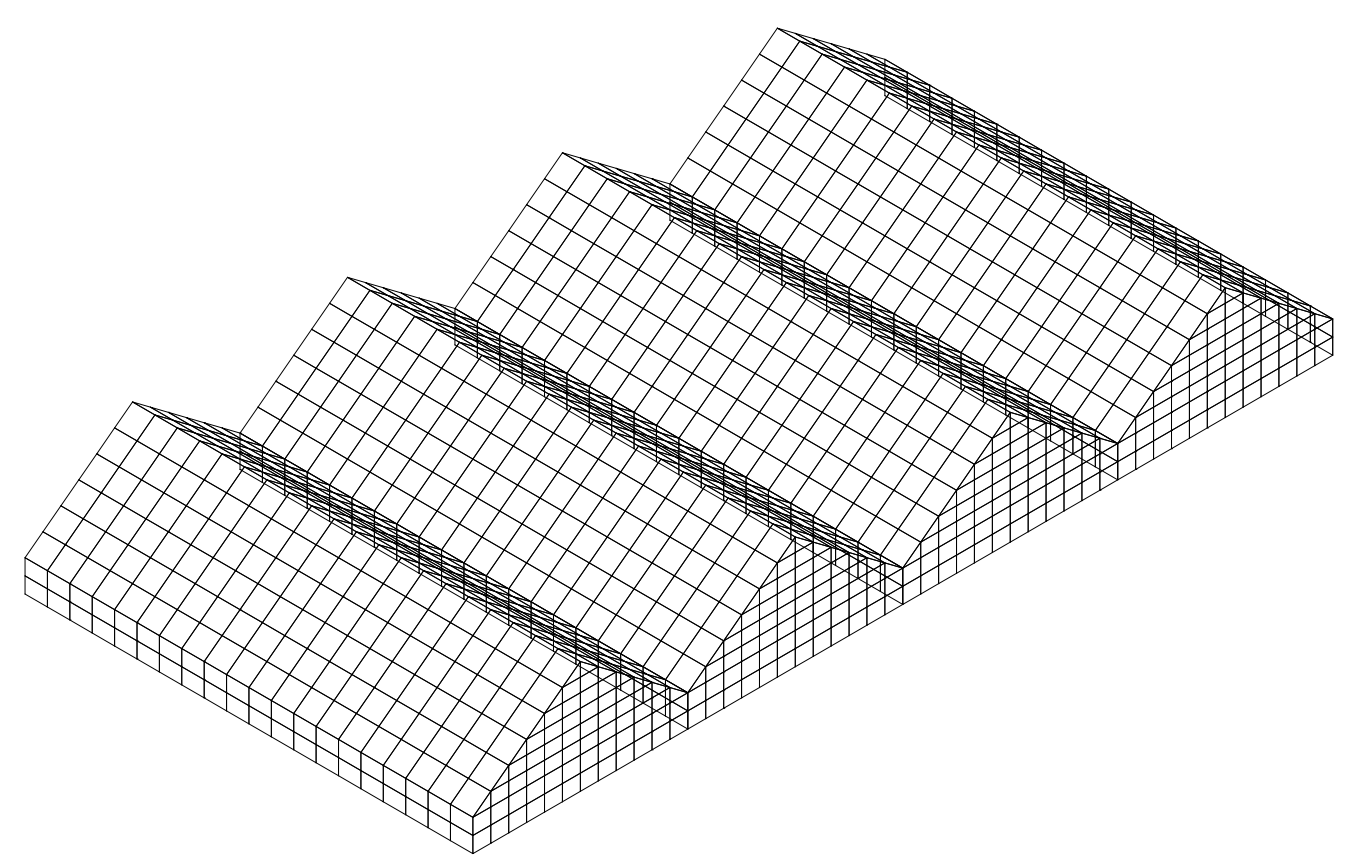

Figure 22: 3-d mesh for 3-d analysis.

Figure 25 (a), and (b) shows the effect of various cross-sections and inclined plate angles on transverse moments of node $\mathrm{d}$. All the values of moments are negative, but the value of moments at $10 \mathrm{~m}$ and $5 \mathrm{~m}$ by space method shows a slightly big than traditional method. The values of moments at dia and $1 \mathrm{~m}$ at one vent case are near to zero. The values of moments at 4 -vents case in $1 \mathrm{~m}$ are close to traditional method values.

Figure 26 (a), and (b) shows the effect of various cross-sections and inclined plate angles on longitudinal moment of plate bd. It is clear the close and small values of moments at space method. The traditional method and space method values are diverging and inverse in singe. Also the values of moments in space method at diaphragm (dia) are negative in all angles. In the case of one vent the same manner of the moments except in diaphragm that is smaller than that in 4 vents case and also negative sign.

Figure 27 (a), and (b) shows the effect of various cross-sections and inclined plate angles on stresses of node a. It is clear the differences in values between traditional method and space method in all values of moments in all angle. Also the close values of stresses in space method specially the values at $5 \mathrm{~m}$, and $10 \mathrm{~m}$ from diaphragm in all angles. The values of stresses at diaphragm and $1 \mathrm{~m}$ in all angles are negative, that because node (a) is at the support of the diaphragm. In the case of one vent the same manner of the stresses. 


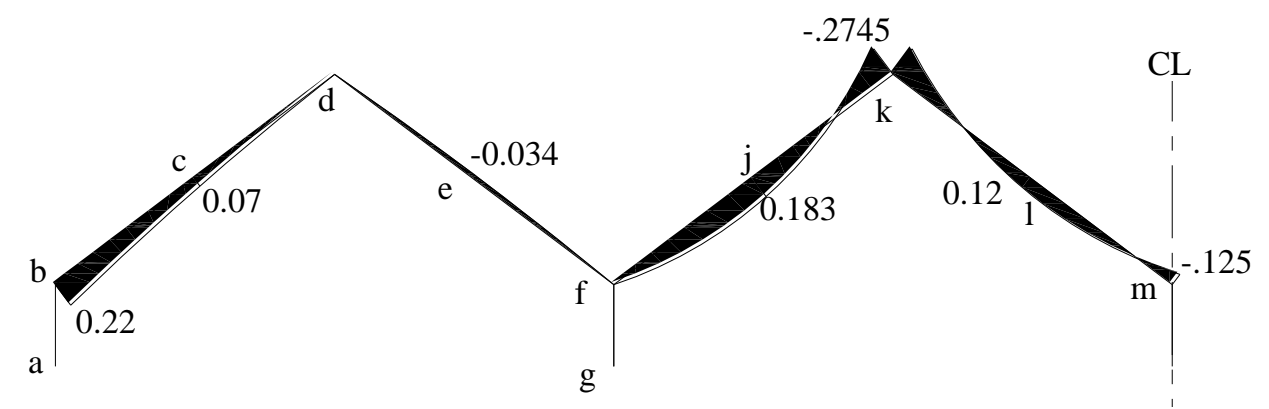

(a) Moment in transverse direction (slab action)(m.t)

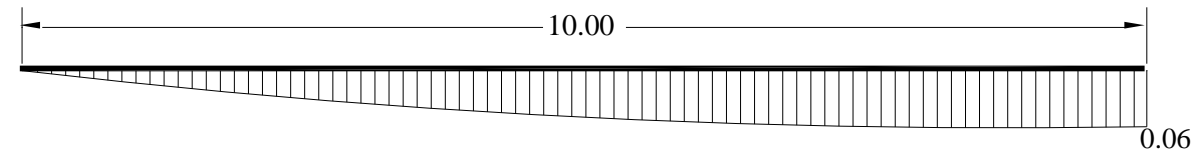

(b) Moment in longitudinal direction for plate bd (beam action) (m.t)

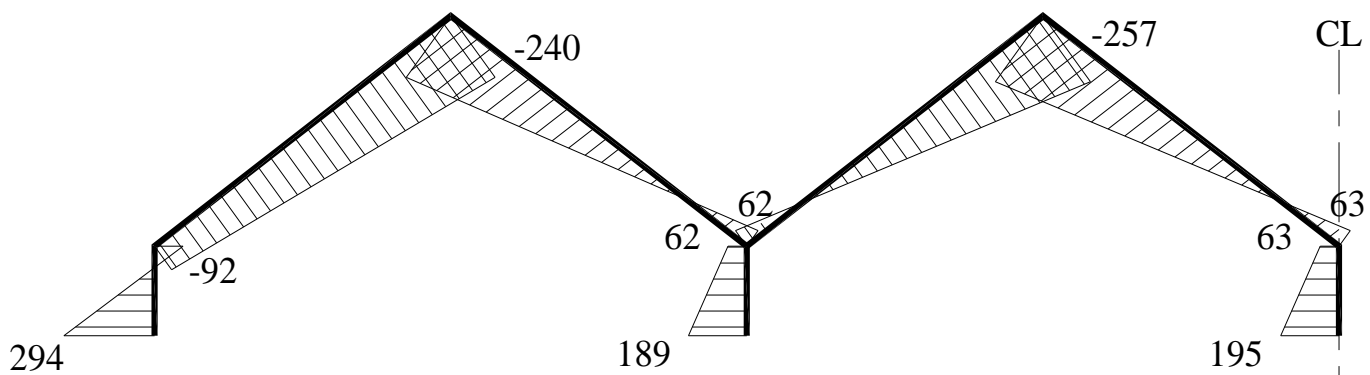

(c) Stresses in transverse direction in mid span $\left(\mathrm{t} / \mathrm{m}^{2}\right)$

Figure 23: 3-D analysis method actions.

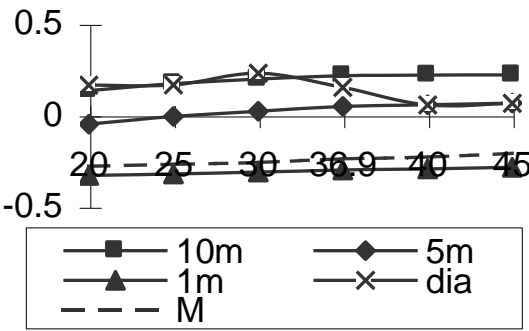

(a) One Vent

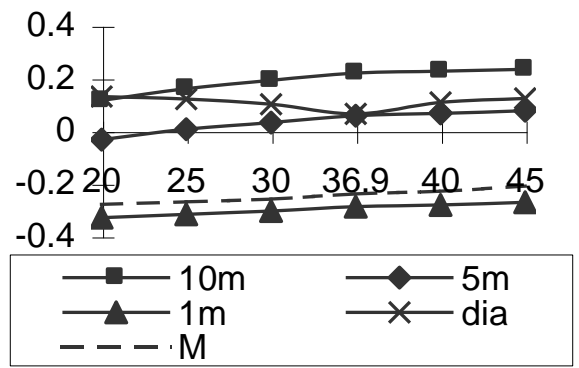

(b) Four Vents

Figure 24: Effect of various cross-sections And inclined plate angles on Transverse moments of node b (m.t). 


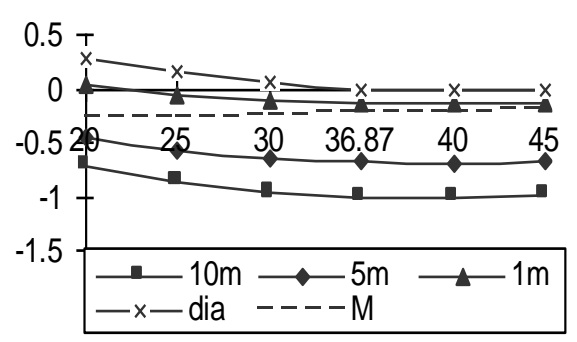

(a) One Vent

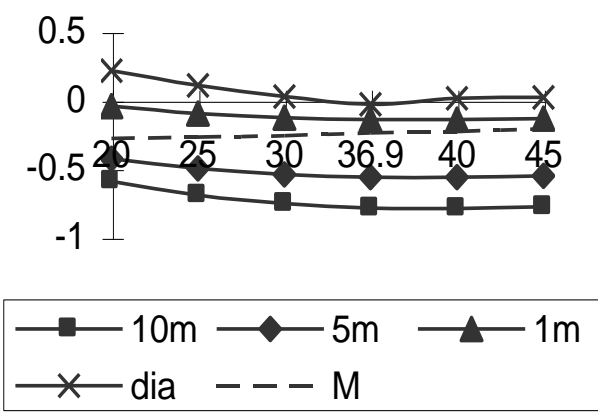

(b) Four Vents

Figure 25: Effect of various cross-sections And inclined plate angles on Transverse moments of node d (m.t).

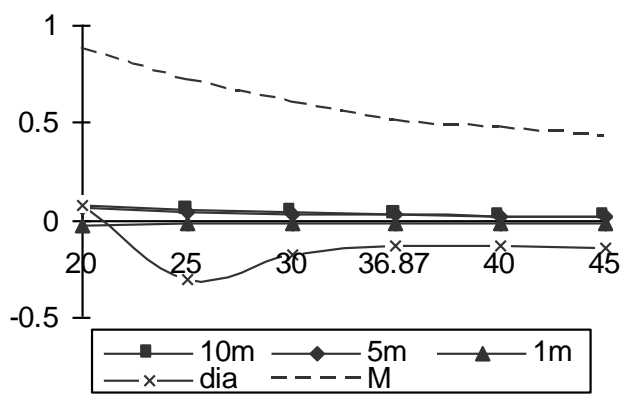

(a) One Vent
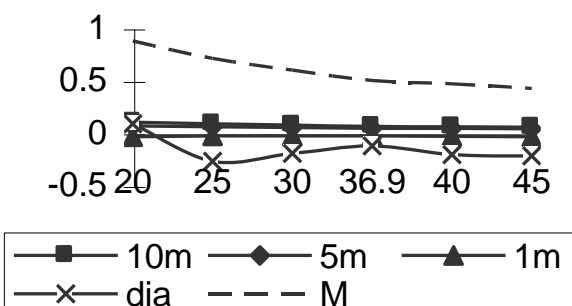

Figure 26: Effect of various cross-sections

And inclined plate angles on longitudinal moments of plate bd (m.t).

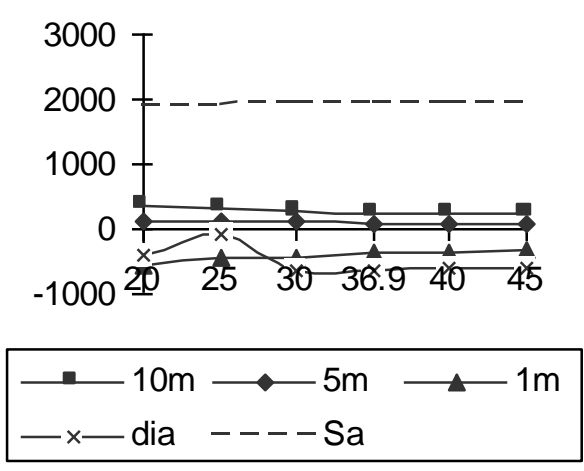

(a) One Vent
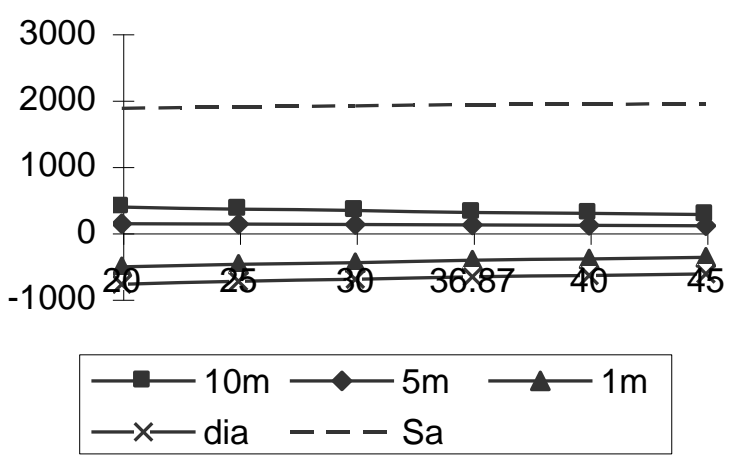

Figure 27: Effect of various cross-sections And inclined plate angles on stresses of node $a\left(t / \mathrm{m}^{2}\right)$. 
Figure 28 (a), and (b) shows the effect of various cross-sections and inclined plate angles on stresses of node $b$. the close values of stresses in space method in all angles are shown and these values are all positive and small comparison with traditional method stresses values.

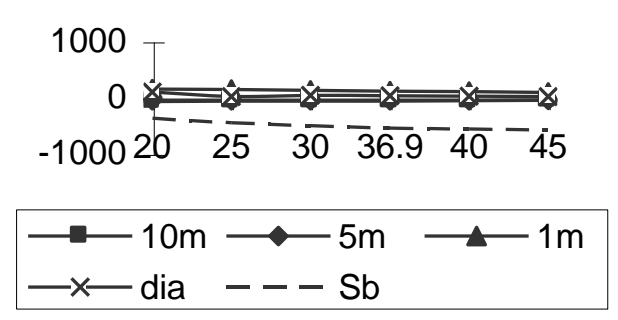

(a) One Vent

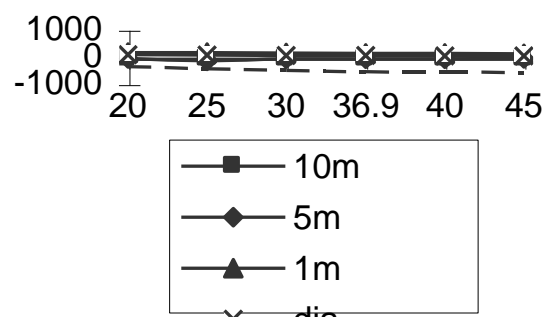

(b) Four Vents

Figure 28: Effect of various cross-sections And inclined plate angles on stresses of node b (m.t).

Figure 29 (a), and (b) shows the effect of various cross-sections and inclined plate angles on stresses of node $b$. It can be recognized the close values between stresses in space method at one vent case and 4-vents case in all angles at diaphragm and $1 \mathrm{~m}$. The values of stresses in space method are small in all angles comparison with the large values of traditional method stresses.

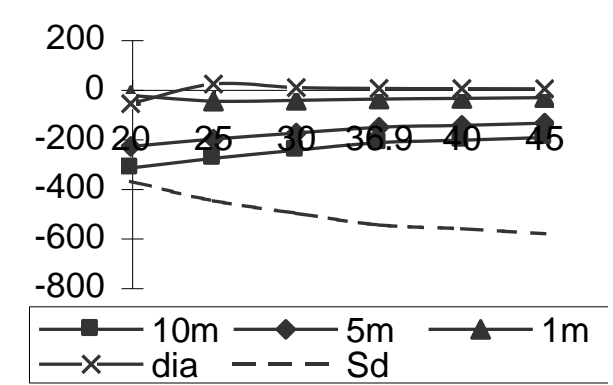

(a) One Vent

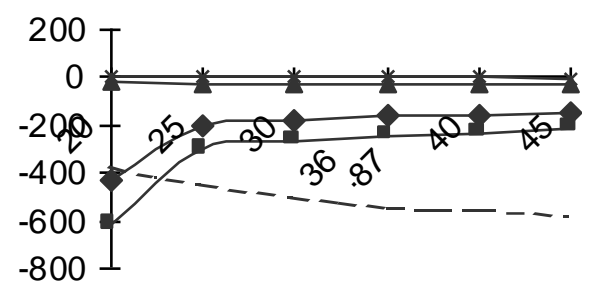

(b) Four Vents

Figure 29: Effect of various cross-sections And inclined plate angles on stresses of node $d\left(t / \mathrm{m}^{2}\right)$

\section{ii-3- Analysis of results}

Transverse moments for node $\mathrm{b}$ as shown in figure $\mathbf{2 4}$ (a), and (b) reflect the fail of traditional method assumption, the intersection of plates act as rigid supports, so the values at all angles are positive except the values of moments at $1 \mathrm{~m}$ because of the effect of the diaphragm and near to supports, this for one vent and 4-vents cases. 
Transverse moments for node $\mathrm{d}$ as shown in figure 25 (a), and (b) show the close values of transverse moments at $1 \mathrm{~m}$ in space analysis and traditional method, but the values of moments at $5 \mathrm{~m}$ and $10 \mathrm{~m}$ are biggest than traditional method but all values are negative (the node behave support condition). The difference between the two methods (space and traditional methods) in longitudinal moments as shown in figure 21(b), and figure 23(b), that because of the traditional method assume that the total load acts on the nods and then distribute on the inclined, horizontal, and vertical plates, these give a large value of longitudinal moments and the plates are simply supported on the end diaphragms neglecting the effect of moment between diaphragm and plates, but in the space method predicted longitudinal moments are smaller by $70 \%$ in plate bd.

It is expected that there would be a difference between stresses in both methods since the solution algorithms vary. For node a in traditional method the stress is more than 6 times bigger than that predicted from space method, but for node $\mathrm{f}$ is less than traditional method by 4 times. For node $b$ the stresses by traditional method are inverse in singe with stresses of space method, this again because of the effect of 3 diminsion displacements of this node. For node $f$ in first vent stress is small and have inverse singe with respect to traditional method this because of the large lateral displacements of node $\mathrm{f}$. for node $\mathrm{d}$ in traditional method stress is small by 6 times than that predicted from space method in second vent, but smaller by 3 time for equivalent node $\mathrm{j}$.

Another comparison is made between the moments calculated using the traditional method and predicted by the space. In that respect, for six angles, 4-vents, and 1-vent evaluated in the study, the space method predicts transverses moments very similar to those given by the traditional method analysis in all angles.

For 4-vents and 1-vent, the traditional method gives longitudinal moments very big, with respect to space method. For one-vent longitudinal moments of plat bd for various inclined angles are close values and either close to that predicted from traditional method, but in 4-vents case even these values are close but smaller than that predicted from traditional method, this observation refers to the effect of number of vents.

For stresses of node a the same approach of 1-ven and 4-vents cases in space method at all angles and the big differences value between them and traditional method, the biggest negative differences are at diaphragm curves, that because node (a) is the supports of end diaphragms. The values of stresses of node a in space method are positive in all angles at mid span and $5 \mathrm{~m}$ distances, and negative in both curves of $1 \mathrm{~m}$ and diaphragms because it is close to diaphragms, but traditional method consider all stresses at node a at all angles are positive.

\section{CONCLUSIONS}

As shown in the previous section, the stresses and moments can vary between the different analysis procedures. First, the stresses and moments are calculated using commercially traditional analysis and space method using FEM computer program (SAP2000). Next, the moments predicted by the space analysis programs are compared to the moments calculated using the traditional method. 
The limitations and reliability of the traditional method procedure as well as space should be fully understood so that adequate conservatism can be incorporated into a design.

A spacer analysis is necessary for a thorough analysis and appropriate design of a structure and while computer programs ease the intensity of the analysis, it is important for the engineer to understand the solution procedure and carefully evaluate the space analysis method.

When comparing stresses and moments computed in the 1-vent and 4-vents cases models, and traditional method (i.e., the exact solution using sequential construction simulation, and the approximate traditional solutions), the moments varied by around $100 \%$ and $150 \%$ in the longitudinal moments in plate bd and plate de. When comparing bending moments and stresses, some important moments and stresses not only varied by more than $100 \%$ between the exact and approximate traditional solutions, but also in addition, sign changes in the moments an stresses occurred in some plates between the exact and approximate solutions.

Furthermore, the approximate traditional analysis procedure for full load where axial deformations were ignored (i.e., which is a common assumption in various "structures analysis" computer programs) was found to be a seriously flawed procedure.

This study reconfirmed that the only valid approach for correctly analyzing these structures for static loads which are analyzed using full 3D analysis procedures, and considering all deformation influences (i.e., not ignoring deformation effects), is to use the sequential construction simulation model.

The computations of displacements were essentially for the exact and approximate rigid connection model neglecting deformations. This study also confirmed that for the case space analysis, the rigid connection model is far too simplistic in its representation of actual behavior for these structures with irregular geometry, concentrations of stiffness, and other irregularities that are completely inconsistent with the assumptions inherent in the rigid connection model. Performing such approximate analysis can result in significant errors.

In conclusion, unless these structures model is highly regular, it was clear from the study that the use of approximate traditional analysis techniques which are based on highly arbitrary assumptions of folded plates behavior can lead to totally incorrect solutions to the distributions of forces throughout the structure. In particular, if only approximate techniques are used, the structural engineer has absolutely no idea whether or not the solutions obtained are anywhere near the correct solutions. In fact, the study demonstrated that the difference between the "exact" space solution and the solutions obtained from several commonly used approximations (such as the rigid connections model, or deformations are ignored, etc.) could be very large (on the order of hundreds of percent in error!).

Unless the engineer is totally aware of the details of all assumptions included in an approximate solution technique, and unless the engineer is completely aware of the consequences of performing analysis on the basis of such assumptions, and unless the engineer knows the correct analysis solution to which the approximate solution can be compared, it is extremely dangerous and a coast to use such approximate analysis methods. 
The increasingly common use of approximate analysis of these structures today is very coast in view of the fact that such structures generally have high aspect ratios, incorporate exceedingly complex and highly irregular geometries, are characterized by highly non-uniform stiffness distributions throughout the structure, are often designed with large open interior atrium spaces, and are designed to use far less volumes of structural materials than were used for these structures in the days before computers, and thus have inherently lower factors of safety in design(Emkin, 1998)[4].

Therefore, it is clear that approximate method of analysis for folded plates structure is suitable only for very preliminary analysis and design purposes. In order to obtain a reliable and safe final structural design of such structures, the most "exact" methods (space method) of analysis that are available today must be used.

In triangular and trapezoidal folded plates can be analyzed any number of vents structures same as one vent using space method, the values of stresses give from space method are small with respect to traditional method but using traditional method when reducing the values of its stresses by $70 \%$ to give the same true values of space method.

\section{REFERENCES}

[1] Peter Jan Pahl, Jochen Hanff, European Conference on Computational Mechanics ECCM '1999, August 31 - September 3 "Consistent Mapping of CAD-Models to FEM-Models"

[2] M. Hilal "Design of Reinforced Concrete Halls"J. Marcou\& Youssef Ess, Inc. 1987

[3] SAP2000 Analysis Reference, Volume 1, Version 6.1 (1997) Computers and Structures, Inc.,Berkeley, CA, pp. 362-369

[4] Leroy Z. Emkin, Ph.D., P.E. (February4, 1998) "Comparison Of Static Analysis Results Based On Different Models Of A 67 Stories Commercial Building”

\section{تقييم استخدام الحل و التصميم بالطرق التقليديه للبلاطات اللوحيه من خلال مقارنتها بالتحليل في ثلاثة ابعاد البلاد}

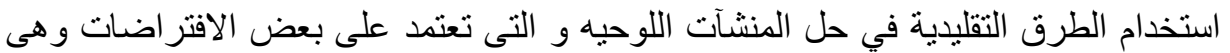

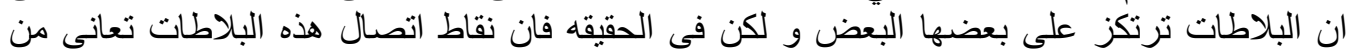

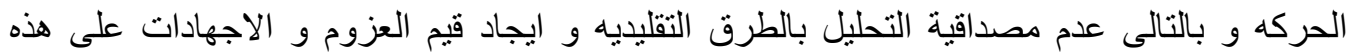

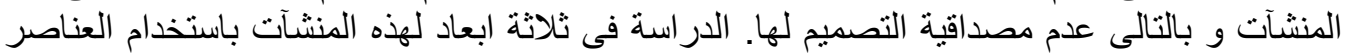

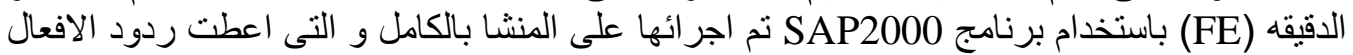

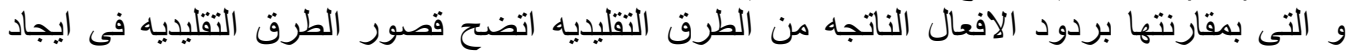

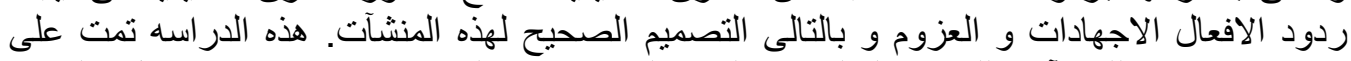

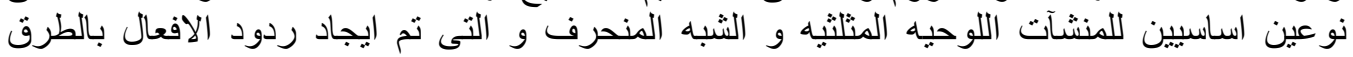

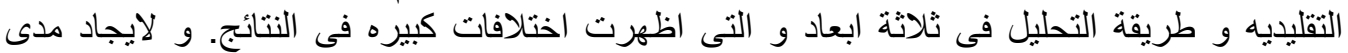

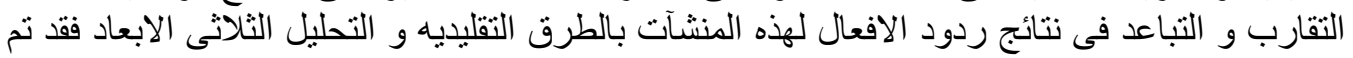

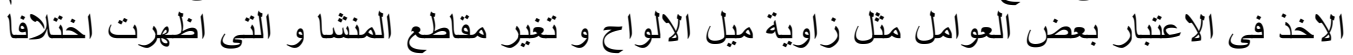

